\title{
AN EXPANDED CONCEPTUALIZATION OF "SMART" CITIES: ADDING VALUE WITH FUZZY COGNITIVE MAPS
}

\author{
Bárbara P. Miguel, Fernando A. F. Ferreira, Audrius Banaitis, \\ Nerija Banaitienè, leva Meidutè-Kavaliauskienė, Pedro F. Falcão
}

\section{Introduction}

The world's population continues to increase rapidly, and, within the next 30 years, more than half of all people will choose to live in large urban centers (Faria et al., 2018). This has led to a number of problems, such as congested people and transportation traffic and increased pollution that produces climate change. The concept of "smart" cities has emerged as a way to deal with these issues, in which these cities are defined as an ecosystem that seeks to improve citizens' quality of life through a combination of technology, sustainability, and physical infrastructures (Estrada et al., 2018). Smart cities have to use new technologies ranging from the Internet of Things (IoT), which facilitates connections between everything, to home automation (i.e., the ease with which citizens can manage daily routines through their homes).

At a commercial level, these cities promote economic growth by developing smart solutions that make businesses more prosperous and efficient. Smart cities also play an important role on a social level since their main objective is to improve residents' quality of life - although citizens must be willing to accept these innovations (i.e., become "smart"). In addition, these cities are essential to the preservation of the environment as they focus on coping with the scarcity of natural resources by using tenable alternatives. Thus, through a combination of social and economic aspects and environmentally friendly practices, these cities should be able to fulfill their purpose as long as they make the best decisions.

To make more informed and efficient decisions, smart cities need to be able to evaluate how well they are doing. Various studies have sought to understand which indicators should be considered in assessments of smart cities and how this process should be conducted. Thus far, researchers have found that using "loose" indicators, which measure only some areas of these cities, is insufficient. The present study, therefore, developed an innovative, integrated cognitive structure that facilitates the evaluation of smart cities in multiple dimensions. More specifically, this research used cognitive mapping to provide a more holistic, expanded understanding of the concept of smart cities. No previous work has been found in the relevant literature that used the fuzzy cognitive mapping approach in this research context. Thus, the proposed methodology makes a significant contribution to the extant literature on smart cities, strategic planning, and operational research and/or management science (OR/MS).

The process followed comprised several stages, including the development of a fuzzy cognitive map (FCM) based on the direct contributions of a group of specialists in this field, as well as static and dynamic analyses of the map's variables. The results show that the construction of an FCM in this research context not only reduces the number of omitted evaluation criteria but also produces a deeper understanding of the cause-andeffect relationships between the determinants identified. The final outcome is a well-informed framework validated by expert panel members, which allows for an objective analysis of the dynamics behind smart cities' characteristics and/or components.

The rest of this paper is organized as follows. The first section offers an overview of the literature on smart cities. Section two introduces the methodology. Section three describes the processes followed in the construction and testing of our FCM-based framework. Finally, the last section concludes the paper and indicates paths for further research. 


\section{Theoretical Overview and Research Gap}

Since the beginning of the twenty-first century, the substantial growth of the world's population has led to increased urbanization in more developed economies. According to Albino et al. (2015) and Hajduk (2016), about $70 \%$ of the world's population will probably reside in large urban centers by 2050. Larger populations in cities can create less favorable demographic, social, economic, and environmental conditions for citizens, including congested people and transportation traffic and increased pollution, which produces climate change. The combination of these undesirable conditions gave rise to the concept of smart cities.

Various authors have attempted to define this concept. Bakici et al. (2013, p. 139), for instance, define a "smart city as a high-tech intensive and advanced city that connects people, information and city elements using new technologies in order to create a sustainable, greener city, competitive and innovative commerce, and a recuperating life quality". Popescu (2015), in turn, considers smart cities to be synergistic ecosystems that seek to improve their quality of life and economy, in which technology plays a predominant role. This definition was reinforced by Cauchon (2017), who states that this type of city uses technologies to automate municipal functions in order to make the societies involved more habitable, economically stable, and environmentally sustainable.

To make a city truly smart, real-time data need to be accessible in many situations in that municipality - a service that can be provided by the IoT. According to Sofronijević et al. (2014, p. 12), this technology "is a new vision of [an] overarching communication paradigm involving purposeful communication and bidirectional transfer of data through [...] Internet connectivity among different objects or things in our environment". On a practical level, the loT is related to the existence of sensors incorporated into the environment, through which information is exchanged and transformed both vertically and horizontally on specific platforms in order to develop a common digital vision of the environment (Sofronijević et al., 2014).

According to Mallapuram et al. (2017) and Roman (2018), smart cities can have multiple dimensions: (1) smart economy; (2) smart governance; (3) smart mobility; (4) smart environments; (5) smart people; and (6) smart lifestyles. As Khatoun and Zeadally (2016) point out, these cities have many advantages. They offer greater protection and safety through the use of, for example, street surveillance cameras and rapid response emergency services. Smart cities show greater concern for the environment and transportation networks, taking into account pollution levels and street lighting and promoting public transportation as an alternative to private cars. These cities also carefully manage domestic energy and take greater care with education facilities, including making new investments and offering opportunities for everyone. In addition, they pay greater attention to tourism to ensure it takes into account the preservation of natural resources. Finally, smart cities are more concerned about keeping their citizens healthy, using new technologies to implement more efficient systems for better access to higher quality services.

Nevertheless, some challenges and/or problems need to be taken into account in the development of smart cities. They require large initial investments, which may lead municipalities to avoid them. These cities can have high levels of energy consumption due to already existing technologies. Furthermore, citizens may not be "smart" enough and refuse to accept the use of technologies to automate the functions of their daily life. Citizens' privacy may also be endangered by cyberattacks (Khatoun \& Zeadally, 2016).

Despite the initial investment required, making a city "smarter" has a positive impact on economic development. According to Chuan-Tao et al. (2015), the introduction of smart solutions enables businesses to become more prosperous, improve their efficiency and quality of management, and increase the use of logistics platforms and more efficient supply chains. Smart cities also allow advertising to be broader and more precise, thereby enabling networks of partners and customers to expand, facilitating entrepreneurship, launching new investments, and promoting innovation.

In addition to economic components, citizens' social issues are also quite important in these cities. Šiurytè and Davidavičienè (2016) report that, to be smart citizens, individuals have to accept the application of new technologies in their daily activities in order to simplify the use of various services. Since residents are 
considered one of the main components of smart cities, their wellbeing must be promoted, which includes increasing home automation that enhances the ease with which citizens manage their daily activities throughout their home. Residences with these types of daily management tools are called "smart" homes because they have an automatic system that permits the control of different objects through commands or smartphones (Toschi et al., 2017).

Both economic elements and citizens are important in the development of these cities, but they can only achieve their goals by reconciling policies with environmental sustainability (i.e., becoming green). Smart cities need to make decisions that ensure economic development, citizens' wellbeing, and a sustainable environment. These decisions can be facilitated through various methods of evaluating smart cities.

The need to measure how "smart" cities are has given rise to several studies and different evaluation procedures using indicators (Dall'O' et al., 2017). The contributions made to date in this area have been quite important to improving evaluations of smart cities. However, the various assessment tools in existence are based on different types of indicators that only measure specific parameters of these cities, such as sustainability, energy efficiency, or pollution. Ahvenniemi et al. (2017) report that these indicators generally seek to assess sustainability, but other indicators are also needed to assess social and economic aspects.

The cited authors argue that evaluations of smart cities' performance should not be done using indicators that only measure the efficiency of implementations of smart solutions. Assessments should also include indicators that measure these solutions' contribution to smart cities' final objectives in terms of environmental, economic, and social sustainability. In other words, most of the indicators currently used are "loose" and non-integrated, which indicates that an integrated, robust, and coherent evaluation framework is still unavailable to facilitate a holistic assessment of smart cities (Huovila et al., 2017).

Given these findings, new evaluation systems clearly need to be developed that incorporate different types of indicators that can ensure a reliable assessment of what truly is "smart" in cities. This is precisely what the present study sought to do. By applying fuzzy cognitive mapping techniques in this research context, we obtained an expanded and integrated understanding of the cause-andeffect relationships between the determinants of smart cities' success. These insights were the result of a well-informed framework that facilitated analyses of the dynamics behind smart city characteristics and/or components.

\section{Methodology}

\subsection{Brief Background on Cognitive Mapping}

Cognitive mapping is defined by Wong (2010, p. 288) as the "process of a series of psychological transformations by which [an] individual acquires, codes, stores, recalls, and decodes information about the relative locations and attributes of phenomena in [... his or her] everyday spatial environment". The result of this process is generally referred to as a "cognitive map". Cognitive mapping can thus be viewed as a mental structuring process that leads to the creation of a cognitive map (Wong, 2010).

The term "cognitive map" was coined by Tolman (1948) to describe individuals' internal mental changes and their representation of the relationships between concepts. Swan (1997, p. 188) reinforces this idea by defining cognitive maps as "internally representing schemas or mental models for particular problem-solving domains that are learned and encoded as a result of an individual's interaction with their environment". Cognitive mapping is thus used to structure complex situations because this method allows researchers to model cause-andeffect relationships between existing variables in complex phenomena. In addition, as visual tools, cognitive maps facilitate representations and communication of knowledge, support the identification and interpretation of information, enable consultation and codification, and stimulate mental associations (Gavrilova et al., 2013; Fernandes et al., 2018; Marques et al., 2018; Oliveira et al., 2018).

Ferreira et al. (2016a) and Ribeiro et al. (2017), along with many other researchers, report that cognitive maps have two main functions. The first is a descriptive function, namely, to provide visual representations that help individuals to understand better the problem in question and thus facilitate its resolution. The second is a reflection function, in which maps are a tool used to develop new ideas. 


\subsection{Cognitive Maps and Fuzzy Cognitive Maps}

Cognitive maps are representations of individuals' environment, providing pictures of reality and helping people to understand causeand-effect relationships between concepts or variables (Tegarden \& Sheetz, 2003; Ribeiro et al., 2017). Usually, a simple cognitive map contains nodes, which stand for concepts, variables, and/or criteria, and arrows, which represent these components' cause-and-effect relationships. Fig. 1 provides an example of a simple cognitive map.

\section{Fig. 1: Example of a simple cognitive map}

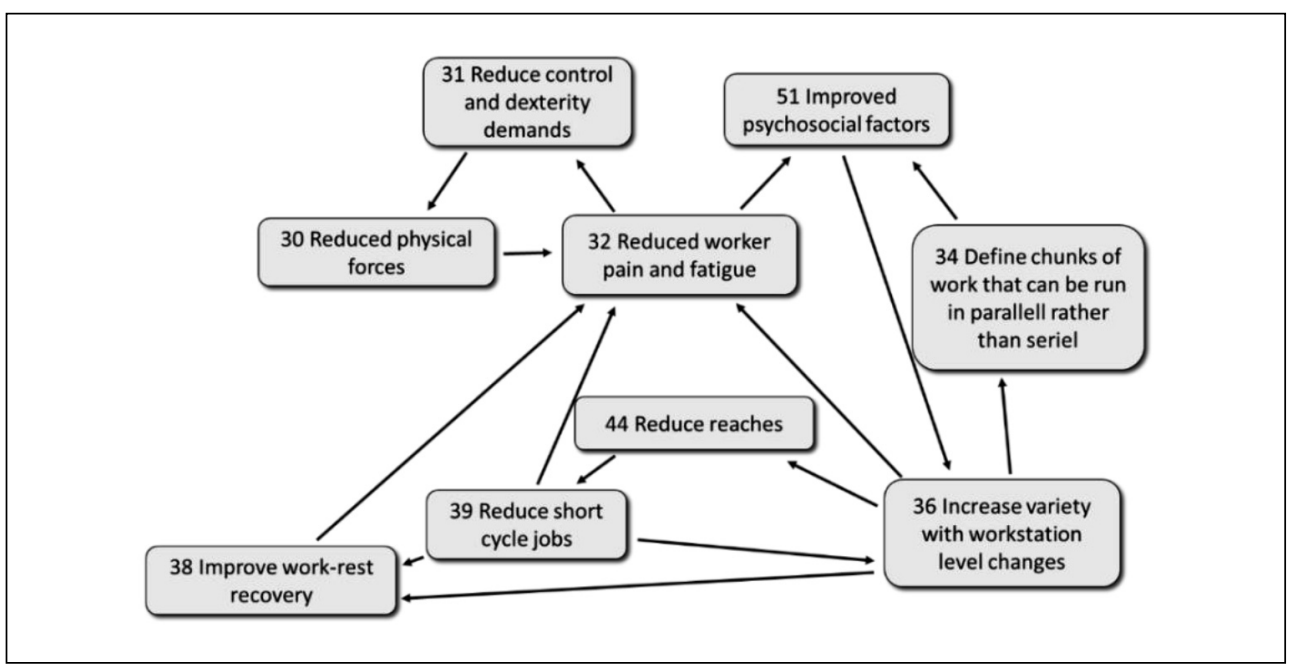

The term fuzzy cognitive map (FCM) was introduced by Kosko (1986) to describe cognitive maps that follow a fuzzy logic. As Zadeh (2008), Keršulienè and Turskis (2011) and Pires et al. (2018) note, logic is important for decision making in complex environments, in which objectives and/or constraints are necessarily fuzzy (i.e., no clearly defined boundaries). As extension of traditional cognitive maps, FCMs are seen as "a well-established artificial intelligence technique, incorporating ideas from artificial neural networks and fuzzy logic, which can be effectively applied in the domain of management science" (Carlucci et al., 2013, p. 208).

Because FCMs combine traditional cognitive maps with fuzzy logic, FCMs have two main characteristics. The first is causeand-effect relationships between concepts and/or criteria that follow a fuzzy logic. That is, the relationship between two different criteria is simultaneously represented by a positive and/or negative causal signal and a number varying from -1 to 1 that represents the degree of intensity and/or influence of the relationship. The second characteristic is that the system is dynamic because it involves feedback links between the criteria, allowing temporal aspects to be considered in the decision structure (Khan \& Quaddus, 2004; Ferreira et al., 2015; Santos et al., 2018). Fig. 2 exemplifies an FCM, in which $C_{i}$ represents the criterion $i$ and $w_{i j}$ represents the intensity of the connection between two criteria $i$ and $j$.

Three possible types of cause-and-effect relationships exist between criteria or concepts: (1) positive causality $\left(w_{i j}>0\right)$; (2) negative causality $\left(w_{i j}<0\right)$; and (3) null causality $\left(w_{i j}=0\right)$ (for further discussion and theoretical details, see also Lee and Lee (2015) and Jorga et al. (2018)). In addition to a graphic representation, 


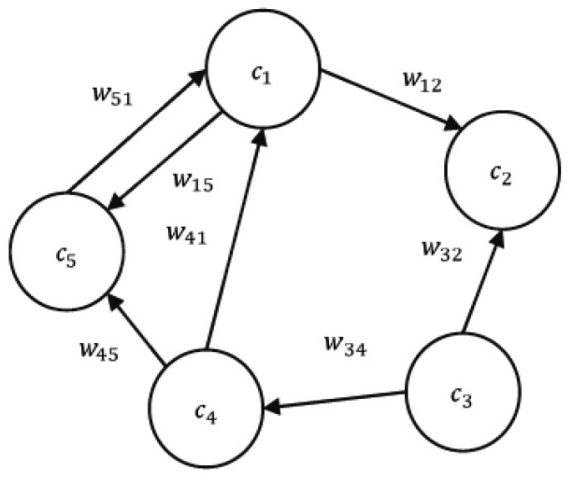

Source: Chen and Chiu (2016, p. 699)

FCMs are also based on mathematical principals. According to Mazlack (2009), these maps include a state vector $n \times 1$ (i.e., $A$ ), which comprises the value of $n$ concepts, and a matrix of intensity degrees $n \times n$ (i.e., $W$ ) - also known as adjacent matrix - in which $w_{i j}$ represents the degree of intensity of the relationships between $n$ criteria (i.e., C). Ribeiro et al. (2017) specify that the matrix $W$ has $n$ rows and $n$ columns, in which $n$ is equal to the total number of concepts in an FCM. Tab. 1 offers an example of an adjacent matrix.

Kok (2009) states that non-zero values may appear on the main diagonal of the adjacent matrix, although this diagonal usually presents values equal to zero, so no criterion is selfevident. Thus, the value of each concept is influenced by the values of the interconnected concepts and by its own previous value (Ribeiro et al., 2017). As Albayrak and Albayrak (2016) point out, the state vector $A$ is also updated by the value of the connections between concepts. Carvalho (2013) stipulates, therefore, that updating the value of each concept for the current iteration must occur only after all concepts have been calculated.

This can be represented by Equation (1), which summarizes the fundamentals of the FCM approach:

$$
A_{i}^{(t+1)}=f\left(A_{i}^{(t)}+\sum_{\substack{j \neq i \\ j=1}}^{n} A_{j}^{(t)} \cdot W_{j i}\right)
$$

Mathematically, $A_{i}^{(t+1)}$ is the activation level of the concept or criterion $C_{i}$ at time $t+1$, while $f$

\section{Tab. 1: Example of an adjacent matrix}

\begin{tabular}{l|c|c|c|c|c} 
& $\boldsymbol{C}_{1}$ & $\boldsymbol{C}_{2}$ & $\ldots$ & $\boldsymbol{C}_{n-1}$ & $\boldsymbol{C}_{n}$ \\
\hline $\boldsymbol{C}_{1}$ & 0 & $w_{12}$ & $\ldots$ & $w_{1 n-1}$ & $w_{1 n}$ \\
\hline $\boldsymbol{C}_{2}$ & $\mathrm{w}_{21}$ & 0 & $\ldots$ & $w_{2 n-1}$ & $w_{2 n}$ \\
\hline$\ldots$ & $\ldots$ & $\ldots$ & $\ldots$ & $\ldots$ & $\ldots$ \\
\hline $\boldsymbol{C}_{n-1}$ & $w_{n-11}$ & $w_{n-12}$ & $\ldots$ & 0 & $w_{n-1 n}$ \\
\hline $\boldsymbol{C}_{n}$ & $\mathrm{w}_{\mathrm{n} 1}$ & $\mathrm{w}_{\mathrm{n} 2}$ & $\ldots$ & $w_{n n-1}$ & 0 \\
\hline
\end{tabular}


is the activation function. In turn, $A_{i}^{(t)}$ represents the activation level of the concept $C_{i}$ at time $t$, and $A_{j}^{(t)}$ is the activation level of the concept $C_{j}$ at time $t$. Finally, $w_{i j}$ is the degree of intensity defined for the relationship between both concepts (Stylios \& Groumpos, 1998; Mazlack, 2009; Mls et al., 2017; Ribeiro et al., 2017).

According to Mazlack (2009, p. 6), "the new state vector $A_{\text {new }}$ is computed by multiplying the previous state vector $A_{\text {old }}$ by the weight matrix W". In addition, four types of activation functions exist. These are: (1) hyperbolic tangent $(f(x)=\tan (x))$, which is used when criteria present values between -1 and 1 ; (2) sigmoid $\left(f(x)=1 /\left(1+\mathrm{e}^{-\lambda x}\right)\right)$, which is used when criteria have values in the interval $[0,1]$; (3) bivalent function $(f(x)=0$ or 1$)$; and (4) trivalent $(f(x)=-1,0$ or 1) (Yaman \& Polat, 2009; Papageorgiou et al., 2012; Salmeron, 2012; Glykas, 2013).

Carlucci et al. (2013, p. 213) state that "the resulting transformed vector is then multiplied by the adjacency matrix and transformed until the system converges to a fixed point. Typically it converges in less than 30 simulation time steps". This means that, at the end of these simulations, a ranking (i.e., "impact strength") of the variables emerges, based on which decision makers can better understand the decision problem in question through the FCM's logical structure (Ferreira \& Jalali, 2015). In addition, decision makers can formulate "what if" questions and analyze the impact on the system of changing some variables, for example, adding or removing criteria.

Ferreira and Jalali (2015) underline that the greatest challenge in developing FCMs is the difficulty of obtaining a panel of experts, as well as ensuring the necessary number and duration of group sessions. However, the advantages of this approach to analyzing the dynamics behind the components of smart cities can outweigh these difficulties.

\section{Application and Results}

This section details the empirical component of the present study. That is, we describe how we developed an FCM to analyze the different components and/or characteristics of smart cities.

\subsection{Participants}

FCMs can be developed by a single decision maker or a group of decision makers. However, according to Yaman and Polat (2009, p. 387), "using a group of experts has the benefit of improving the reliability of the final model". Ackermann and Eden (2001) and Ribeiro et al. (2017) advise recruiting between 3 and 10 specialists per decision group to ensure studies are coherent and valid. In the present research, the group sessions included six expert participants, thus respecting the guidelines presented in the literature.

The sessions had an average duration of 3.5 hours each, and the meetings were guided by 2 experienced facilitators (i.e., researchers). Notably, forming the panel was not an easy task due to the incompatibility of participants' agendas. Multiple contacts were established for nearly 3 months to recruit the panel of 6 decision makers who participated in this study. These participants work in Lisbon, Portugal. Two of them were female, and the panel's age ranged between 30 and 50 years old. Their interactions were important to ensure differing points of view were taken into account. The participants joined the panel voluntarily, and they were selected based on their professional experience in different areas of smart cities, such as urban planning, mobility, and citizen wellbeing and healthcare.

The constructivist nature of the proposed methodological approach needs to be highlighted here, given that the focus is on the process rather than the end result (Bell \& Morse, 2013). This suggests that the procedures followed can work well with any group of decision makers. After the panel was formed, the first session was conducted as presented in the following subsection.

\subsection{Development of Cognitive Structure Using "Post-its Technique"}

The first session with the group of experts began with a brief presentation of the main objective of the study, as well as a brief explanation of the methodology to be used. Next, the following trigger question was asked: "Based on your personal values and professional experience, what should the characteristics of the best 'smart city' be?" This question was posed by one of the facilitators to stimulate a debate among the participants, thus creating an environment in which all participants could share their knowledge and experiences.

A tool called the "post-its technique" (Ackermann \& Eden, 2001) was used, which consists of writing the concepts that the panel 
considers most important on post-its - with each concept written on a separate post-it note. This process was continued throughout the group's discussions and negotiations until the panel of decision makers expressed satisfaction with the results achieved (Ferreira et al., 2016b). In this process, the decision makers were always given the option of changing concepts and/or inserting new criteria into the map whenever they felt that the latter did not represent their ideas. This methodology also took into account criteria with a negative influence (i.e., negative causality) during the panel's analysis of the smart city concept. These criteria were marked with a negative sign (-) on the corresponding post-it note (Ferreira \& Jalali, 2015). Throughout the session, the postits were placed on a whiteboard to make them visible to all participants.

Grouping concepts by areas of concern (i.e., clusters) took place in the next phase of the first session and produced six clusters: (1) people, (2) planning and environments, (3) technology, (4) infrastructure and materials, (5) services, and (6) transportation and mobility. The decision makers were then asked to organize the concepts within each cluster in order of greatest importance so that the variables the panel considered most significant in each cluster were placed at the top of the cluster and those that were less significant at the bottom (Ferreira et al., 2016c; Fonseca et al., 2018; Ferreira et al., 2017). Using the Decision Explorer software (www.baxia.com), a group cognitive map was developed based on these clusters, and the decision makers were given the opportunity to change the map's shape and/or content if they did not completely agree with the final result. Fig. 3 presents the final version of this map, which contains more than 200 criteria related to smart cities.

The cognitive map above seeks to structure the panel members' knowledge and experience revealed through their analysis of the smart city concept. As Ferreira et al. (2015) note, the high volume of information discussed and projected on the map arguably more than compensates for the subjective nature of the process. The latter obviously depends on the facilitators' skill, and the results are deeply influenced by the panel members' perceptions. Nonetheless, Ferreira et al. (2016b, p. 1474) contend that "the size of the

\section{Fig. 3: Group cognitive map}

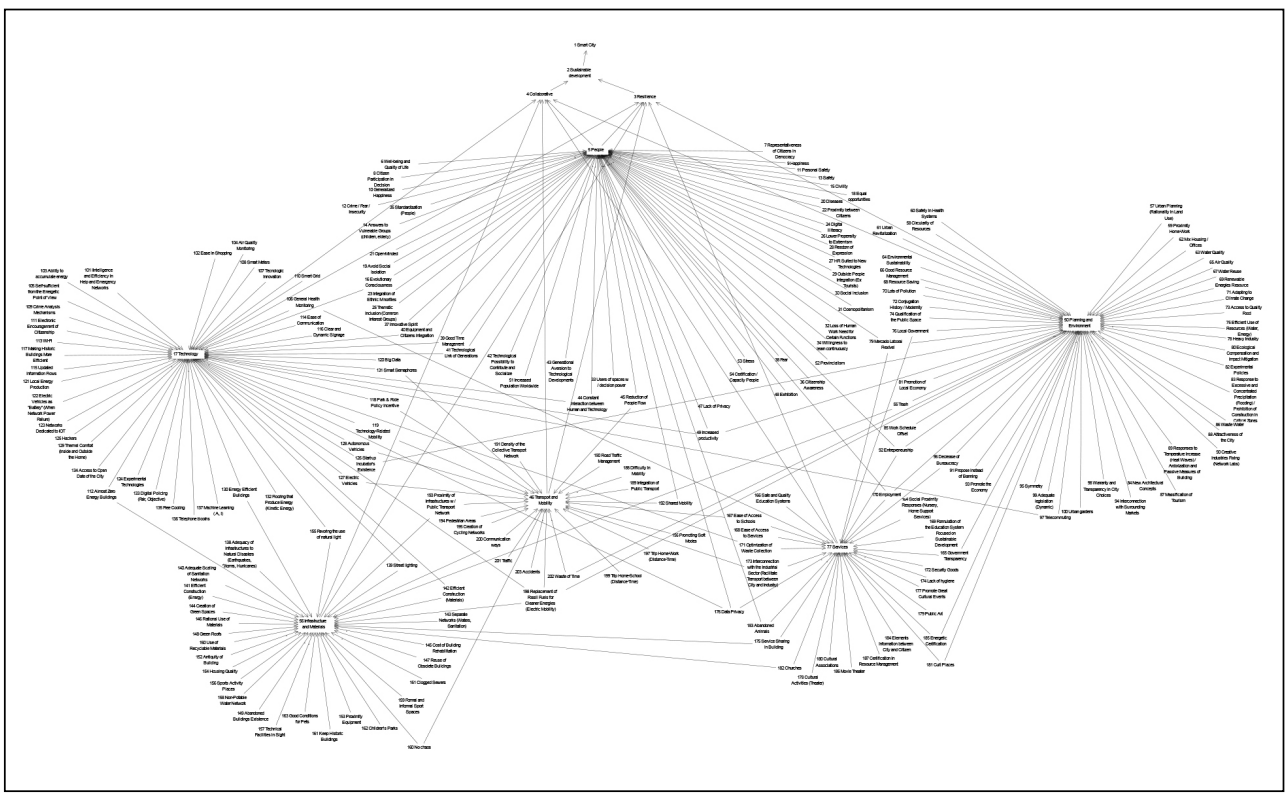


map, the number of variables identified, and the number of inter-relationships among them, are all important indicators of the capability of this type of tool to tap into often overlooked determinants, as well as the relationships between them". In the next session, we analyze the cause-andeffect relationships behind the cognitive structure developed in the first group session.

\subsection{Development of FCM}

The second group meeting was attended by the same six decision makers. In this session, the panel was asked to look at the map and focus on the existing cause-and-effect relationships between criteria so that the concepts' degree of intensity (i.e., influence) could be measured using the interval $[-1 ; 1]$. The session's facilitators had the task of quietly reading concept by concept through the map while the decision makers distributed the values within the defined range - that they collectively found as the most appropriate measures of the relationships between criteria.

Next, the FCMapper (http://www.fcmappers. net) and Panjek (http://pajek.imfm.si/doku.php) software packages were used to include the degrees of intensity defined by the decision makers in the cognitive structure developed. The result was the FCM presented in Fig. 4, which is similar to a neural network. To simplify the figure for this paper, all labels were removed. However, the complete version of the structure, containing all the specifications, is available upon request.

As shown by the example in Fig. 5, the decimal number attributed to each arrow depicts the degree of intensity of the causeand-effect relationship between the head and tail criteria. The cluster shown in Fig. 5 concerns transportation and mobility, and the degree of intensity of each link is measured within the range of $[-1 ; 1]$. The next step was an analysis of the main factors that noticeably influence the dynamics of key components of the ideal smart city.

\subsection{Static and Dynamic Analysis of Results}

Carlucci et al. (2013, p. 216) note that, "through a proper neural network computational model,

\section{Fig. 4: Basic structure of FCM}

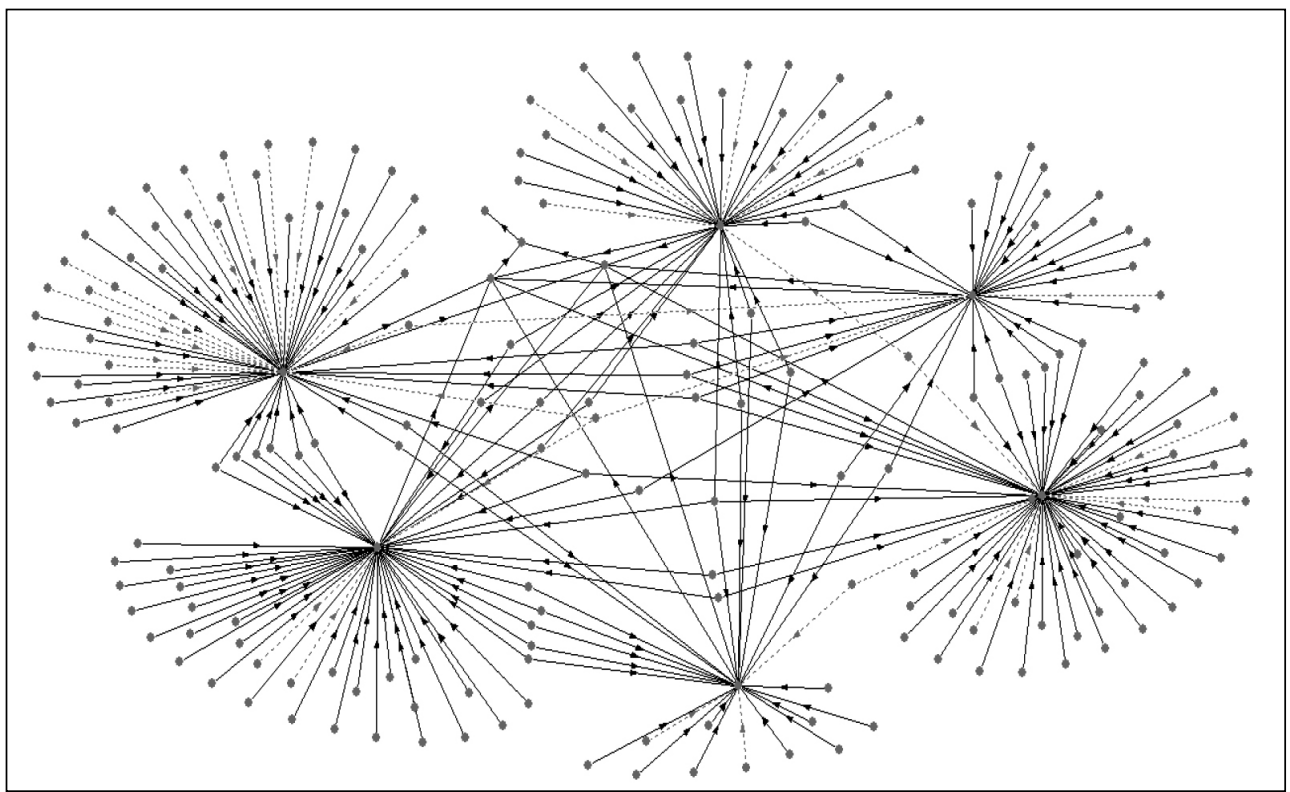




\section{Fig. 5: Analysis of degrees of intensity for transportation and mobility cluster}

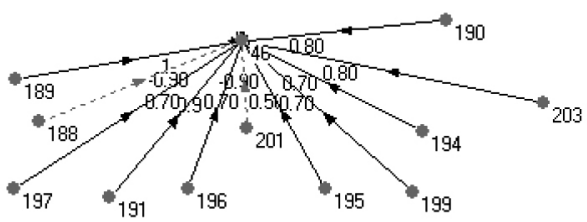

Source: own

[...] what we can get is an idea of the ranking of the variables in relation to each other according to how the system is perceived in the FCM". The present study thus included static and dynamic analyses of the components in the FCM generated.

\section{Static Analysis}

All the criteria presented in the collective FCM have a degree of centrality. However, Tab. 2 presents only those that revealed higher indexes in terms of smart cities. The complete list is available upon request.

As shown in Tab. 2, the key components and/or determinants of smart cities are, first, technology (37.80), followed by people (32.70), planning and environments (29.90), infrastructure and materials (22.00), transportation and mobility (21.40), and services (13.90). The least significant factors for smart cities in this list are resilience (6.00) and collaboration (6.00).
According to Papageorgiou et al. (2012, p. 45), "FCMs are simple, yet powerful tools for modeling and simulation of dynamic systems, based on domain-specific knowledge and experience". Therefore, the present study's analysis of the concepts' degrees of centrality was important not only because the results facilitated a deeper understanding of the system created but also because the primary determinants of the development of smart cities could be identified.

\section{Dynamic Analysis}

To analyze the dynamics behind components of smart cities, we used the Mental Modeler software (http://www.mentalmodeler.org/). Gray et al. (2013, p. 967) report that this tool "provides a way for users to develop a simple qualitative FCM which is then translated into the quantitative structure required to run dynamic FCM scenarios". Following Azevedo

\section{Tab. 2: Degrees of centrality of criteria}

\begin{tabular}{l|r|r|r}
\multicolumn{1}{c|}{ Factor/Criterion } & \multicolumn{1}{c|}{ Outdegree } & \multicolumn{1}{c}{ Indegree } & \multicolumn{1}{c}{ Centrality } \\
\hline Technology & 2.00 & 35.80 & 37.80 \\
\hline People & 2.00 & 30.70 & 32.70 \\
\hline Planning and Environments & 1.60 & 28.30 & 29.90 \\
\hline Infrastructure and Materials & 1.20 & 20.80 & 22.00 \\
\hline Transportation and Mobility & 1.80 & 19.60 & 21.40 \\
\hline Services & 1.40 & 12.50 & 13.90 \\
\hline Resilience & 1.00 & 5.00 & 6.00 \\
\hline Collaboration & 1.00 & 5.00 & 6.00 \\
\hline
\end{tabular}


and Ferreira's (2017) example, we carried out dynamic analyses on three different levels: (1) clusters; (2) inter-cluster links; and (3) intracluster connections.

\section{Dynamic Analysis at Cluster Level}

The clusters' behavior was analyzed in relation to the concepts recognized as transversal to all clusters (i.e., resilience and collaboration). More specifically, three scenarios (i.e., variations of $-0.50,0.75$, and 1.00 ) were simulated in order to evaluate the impact of these crosssectional concepts in the development of smart cities. Significant changes appear in the six clusters when the degrees of intensity of these transversal criteria change.

For the people cluster, an increase in intensity of 0.75 or 1.00 produces an increase in its importance in relation to the concepts collaboration and resilience in smart cities. When this cluster decreases its intensity by -0.50 , its importance in relation to smart cities also decreases. According to the expert panel, smart cities must be resilient and collaborative. The planning and environments cluster presents a degree of intensity of 0.80 in its connection to the concepts collaboration and resilience. Increasing this intensity by 0.75 or 1.00 also results in increases of these two cross-sectional concepts, although of a lesser magnitude. When the cluster's intensity is decrease by -0.50 , the two concepts' importance in relation to smart cities also decreases.

Similar to the people cluster, the technology cluster has an intensity of 1.00 , implying that variations in intensity of 0.75 or 1.00 result in an increase in the importance of the concepts of collaboration and resilience in relation to smart cities. A decrease in intensity of -0.50 in this cluster also diminishes the importance these two cross-sectional concepts in the development of smart cities.

The infrastructure and materials cluster has a slightly lower intensity than the other clusters do (i.e., 0.60). However, with an increase in intensity of 0.75 or 1.00 , the concepts collaboration and resilience also become more important to smart cities. Since the services cluster has an intensity of 0.70 , an increase in its intensity of 0.75 or 1.00 causes the concepts collaboration and resilience to increase in importance regarding the development of smart cities. When this cluster is subject to a negative variation of intensity of -0.50 , cross-criteria tend to become less important for a city to be "smart".

Finally, the last cluster identified (i.e., transportation and mobility) shows an intensity of 0.90 , which makes this cluster one of the most important in the development of smart cities. Thus, when its intensity is increased by 0.75 or 1.00 , the cross-sectional concepts under analysis become more important. In contrast, when it intensity is decreased by -0.50 , these cross-sectional concepts become less important.

The dynamic analysis performed at the cluster level clearly shows the importance that collaboration and resilience have in the development of smart cities. Nonetheless, this study's methodological framework required a further analysis of concepts that affect more than one cluster.

\section{Dynamic Analysis at Inter-Cluster Level}

Given the presence of criteria that connect to more than one cluster, an analysis needed to be conducted of the impacts of these concepts' variations in intensity on the clusters to which they are connected. The specific criteria analyzed were chosen because they present higher and lower intensity degrees within the respective clusters. As in the previous analyses, three variations of $-0.50,0.75$, and 1.00 were simulated.

The analysis started with the concept of almost zero energy buildings, which is clearly part of the technology cluster, although this concept is also connected to the infrastructure and materials cluster. In the second group session, the decision makers assigned the concept of almost zero energy buildings an intensity degree of 1.00 in relation to the technology cluster, and 0.80 in connection to the infrastructure and materials cluster. Variations in the intensity of almost zero energy buildings impact these clusters.

Regarding the concept of presence of start-up incubators in the technology cluster, this concept has an intensity of 0.30 . It also is connected to the planning and environments cluster, with an intensity of 0.40 . Variations in the intensity of this concept affect these two clusters.

Regarding the optimization of waste collection concept in the services cluster, which was assigned an intensity of 0.80 , this concept is also connected to the technology cluster, with an influence degree of 0.70 . In addition, 
the concept of places of worship in the services cluster has a degree of intensity of 0.20 . This concept's connection to the planning and environments cluster also presents the same degree of intensity (i.e., 0.20).

The data privacy concept belongs to the services cluster, with an intensity of -0.40 , and this concept is also connected to the people (i.e., -0.60) and technology clusters (i.e., -0.80). Variations in the intensity of the data privacy concept impact these clusters. With regard to the concept of efficient construction (materials), this is integrated in the infrastructure and materials cluster, as well as having a connection to the technology cluster with the same intensity value (i.e., 0.80).

Finally, the criterion of waste of time is integrated in the transportation and mobility cluster with an intensity of -0.80 . This concept further has a connection to the planning and environments cluster, which has an intensity of -0.50 .

After completing the dynamic analysis at the inter-cluster level, a further level of dynamic analysis was conducted. This focused on the intra-cluster level, as presented in the text below.

\section{Dynamic Analysis at Intra-Cluster Level}

The final dynamic analysis at the intra-cluster level was carried out by simulating intensity variations in some of the criteria in the various clusters. The four criteria that present the highest and lowest intensities in each cluster were chosen. Tab. 3 presents the impacts of variations of $-0.50,0.75$, and 1.00 in the degree of intensity of some criteria in the people cluster.

Tab. 3: Dynamic analysis of people cluster

\begin{tabular}{l|r|r|r|r}
\multicolumn{1}{c|}{ Criterion } & \multicolumn{1}{c|}{ Value Assigned } & \multicolumn{1}{c|}{$\Delta \mathbf{- 0 . 5}$} & \multicolumn{1}{c|}{$\mathbf{0 . 7 5}$} & \multicolumn{1}{c}{$\Delta \mathbf{1 . 0 0}$} \\
\hline Wellbeing and Quality of Life & 1.00 & -0.46 & 0.64 & 0.76 \\
\hline Cosmopolitanism & 0.20 & -0.10 & 0.15 & 0.20 \\
\hline Standardization (Qualifications) & -0.30 & 0.15 & -0.22 & -0.29 \\
\hline Crime/Fear/Insecurity & -0.90 & 0.42 & -0.59 & -0.72 \\
\hline
\end{tabular}

Tab. 4: Dynamic analysis of planning and environments cluster

\begin{tabular}{l|r|r|r|r}
\multicolumn{1}{c|}{ Criterion } & \multicolumn{1}{c|}{ Value Assigned } & \multicolumn{1}{c|}{$\Delta \mathbf{- 0 . 5}$} & \multicolumn{1}{c|}{$\Delta \mathbf{0 . 7 5}$} & \multicolumn{1}{c}{$\Delta \mathbf{1 . 0 0}$} \\
\hline Renewable Energy Resources & 1.00 & -0.46 & 0.64 & 0.76 \\
\hline Proposals Instead of Bans & 0.10 & -0.05 & 0.07 & 0.10 \\
\hline Symmetry & -0.30 & 0.15 & -0.22 & -0.29 \\
\hline Heavy Pollution & -0.90 & 0.42 & -0.59 & -0.72 \\
\hline
\end{tabular}

Tab. 5: Dynamic analysis of technology cluster

\begin{tabular}{l|r|r|r|r}
\multicolumn{1}{c|}{ Criterion } & \multicolumn{1}{c|}{ Value Assigned } & \multicolumn{1}{c|}{$\Delta \mathbf{- 0 . 5}$} & \multicolumn{1}{c|}{$\boldsymbol{0 . 7 5}$} & \multicolumn{1}{c}{$\Delta \mathbf{1 . 0 0}$} \\
\hline Almost Zero Energy Buildings & 1.00 & -0.46 & 0.64 & 0.76 \\
\hline Presence of Start-up Incubators & 0.30 & -0.15 & 0.22 & 0.29 \\
\hline Telephone Booths & -0.20 & 0.10 & 0.15 & -0.20 \\
\hline Hackers & -0.90 & 0.42 & -0.59 & -0.72 \\
\hline
\end{tabular}




\begin{tabular}{l|r|r|r|r}
\multicolumn{1}{c|}{ Criterion } & \multicolumn{1}{c|}{ Value Assigned } & \multicolumn{1}{c|}{$\Delta \mathbf{- 0 . 5}$} & \multicolumn{1}{c|}{$\Delta \mathbf{0 . 7 5}$} & \multicolumn{1}{c}{$\Delta \mathbf{1 . 0 0}$} \\
\hline Efficient Construction (Materials) & 0.80 & -0.38 & 0.54 & 0.66 \\
\hline Good Conditions for Pets & 0.20 & -0.10 & 0.15 & 0.20 \\
\hline Cost of Building Rehabilitation & -0.10 & 0.05 & -0.07 & -0.10 \\
\hline Abandoned Buildings & -0.80 & 0.38 & -0.54 & -0.66 \\
\hline
\end{tabular}

As shown in Tab. 3, the criterion of wellbeing and quality of life presents the highest degree of intensity, with a positive effect on this cluster. In addition, the criterion crime/fear/insecurity has the most negative impact on the cluster in question. Regarding the second cluster (i.e., planning and environments), Tab. 4 presents the simulations carried out on the degree of intensity of some of this cluster's criteria.

As Tab. 4 reveals, the criterion of renewable energy resources is the most significant in this cluster, with a large discrepancy between this concept's degree of intensity and that of the least important criterion (i.e., proposals instead of bans). In contrast, the concept of heavy pollution has the most negative effect on this cluster. This indicates that officials must reduce pollution when developing smart cities. Tab. 5 presents the impacts of variations of $-0.5,0.75$, and 1.00 on the degree of intensity of some criteria in the technology cluster.

As shown in Tab. 5, the almost zero energy buildings criterion presents high intensity, supporting the conclusion that the existence of buildings that are technologically efficient is essential to the development of smart cities. The results also verify that the concept of hackers has greater intensity - but in a negative way - so that combating this threat is extremely important to the sustainable development of smart cities. Regarding the fourth cluster (i.e., infrastructure and materials), Tab. 6 presents the simulations carried out on the degree of intensity of some of this cluster's criteria.

As shown in Tab. 6, the concept of efficient construction (materials) has a degree of intensity of 0.80 , revealing its importance in terms of physical infrastructures of cities that seek to be "smart". Conversely, the concept of abandoned buildings is the criterion that most negatively affects smart cities as this is an adverse factor in terms of the technological efficiency of buildings. Tab. 7 presents the impacts of variations in the degree of intensity for some criteria in the fifth cluster (i.e., services).

Tab. 7 confirms that the criterion with the greatest influence and/or intensity in the services cluster is the optimization of waste collection. In contrast, the least important concept to these cities is places of worship. Regarding negative influence, the criterion that most stands out is lack of hygiene. Tab. 8 shows the variations in intensity of the criteria corresponding to the sixth and last cluster (i.e., transportation and mobility).

As Tab. 8 reveals, the integration of public transportation criterion presents the maximum intensity as this component is needed as an alternative to the use of private cars.

\section{Tab. 7: Dynamic analysis of services cluster}

\begin{tabular}{l|r|r|r|r}
\multicolumn{1}{c|}{ Criterion } & \multicolumn{1}{c|}{ Value Assigned } & \multicolumn{1}{c|}{$\boldsymbol{- 0 . 5}$} & \multicolumn{1}{c|}{$\Delta \mathbf{0 . 7 5}$} & \multicolumn{1}{c}{$\Delta \mathbf{1 . 0 0}$} \\
\hline Optimized Waste Collection & 0.80 & -0.38 & 0.54 & 0.66 \\
\hline Places of Worship & 0.20 & -0.10 & 0.15 & 0.20 \\
\hline Lack of Hygiene & -0.70 & 0.34 & -0.48 & -0.60 \\
\hline Data Privacy & -0.40 & 0.20 & -0.29 & -0.38 \\
\hline
\end{tabular}




\section{Tab. 8: Dynamic analysis of transportation and mobility cluster}

\begin{tabular}{l|r|r|r|r}
\multicolumn{1}{c|}{ Criterion } & \multicolumn{1}{c|}{ Value Assigned } & \multicolumn{1}{c|}{$\Delta \mathbf{- 0 . 5}$} & \multicolumn{1}{c|}{$\mathbf{0 . 7 5}$} & \multicolumn{1}{c}{$\Delta \mathbf{1 . 0 0}$} \\
\hline Integrated Public Transportation & 1.00 & -0.46 & 0.64 & 0.76 \\
\hline Creation of Cycling Networks & 0.50 & -0.24 & 0.36 & 0.46 \\
\hline Waste of Time & -0.80 & 0.34 & -0.48 & -0.60 \\
\hline Difficulty in Mobility & -0.90 & 0.42 & -0.59 & -0.72 \\
\hline
\end{tabular}

Source: own

The concept of creating cycling networks is of less importance. On the negative side, difficulty in mobility is highlighted, but this can be resolved by the integration of public transportation networks. Regarding the concept of waste of time, it has an intensity similar to the previous criterion (i.e., -0.80 ).

After a dynamic analysis of each cluster, the conclusion was reached that several factors positively or negatively influence the development of smart cities. All of these determinants must be taken into account during the process of creating this type of city.

\subsection{Validation, Limitations, and Recommendations}

An FCM was constructed in this study based on the inputs provided by a panel of experts in smart cities. According to Salmeron (2012, p. 3706), "FCMs have [note]worthy characteristics [such] as flexibility, adaptability, fuzzy reasoning and the capacity of abstraction. FCMs have been widely used [...] to model and analyze complex dynamical systems". These benefits justified the use of this methodology to expand the conceptualization of smart cities. This methodological choice was reinforced by Papageorgiou et al.'s (2017, p. 16) findings, as these authors portray FCMs as "an efficient, transparent and easy to use tool for modeling complex systems and decision support tasks".

The construction of the present study's FCM was only made possible by the direct participation of specialists, who guaranteed robust and objective results and proved to be extremely helpful throughout the entire structuring process. Nonetheless, as mentioned previously, the FCM approach has its limitations, especially its context-specificity (cf. Ferreira \& Jalali, 2015). This methodology's contextual dependence means that the proposed model is idiosyncratic and that the present study's results could have been different with another expert panel, other facilitators, and/or longer work sessions.

Regardless of the limitations of this methodology, the process-oriented nature of the approach applied implies that this can be replicated in other contexts and with other decision makers if the procedures followed are carefully adjusted. This flexibility is a reflection of the constructivist stance assumed from the start in the present research (cf. Bell \& Morse, 2013).

\section{Conclusion}

The current study sought to develop an integrated model to evaluate the various dimensions of smart cities. This was achieved by using cognitive mapping techniques to facilitate the development of an FCM. Stach et al. (2005, p. 372) note that "[FCM] development methods are far from being complete and welldefined, mainly because of the deficiencies that are present in the underlying theoretical framework [...T]he development of [... FCMs] almost always relies on human knowledge [...] strongly dependent on subjective beliefs of expert(s) from a given domain".

Thus, the current research strove to overcome FCMs' limitations by using the practical know-how and professional experience of a group of experts in different dimensions of smart cities, such as urban planning, mobility, and citizen wellbeing and healthcare. After an FCM was constructed based on the direct involvement of the expert participants, six main clusters were extracted as key components in the development of smart cities. These clusters were: people; planning and environments; technology; infrastructure and materials; services; and transportation and mobility.

In addition, the development of this FCM relied upon measuring the degree of intensity 
of the cause-and-effect relationships between variables, which ensured greater transparency and versatility in the proposed conceptualization of smart cities. The methodology applied also included the possibility of adding new criteria to portray more accurately the dynamics underlying the model's components. The results provide support for more informed decisions, which are of great interest to urban planners, city administrators, and society at large. No previous study in this field of research was found to have used the FCM methodology, confirming that the present study's approach is innovative and that it makes a positive contribution to the extant literature on smart cities, strategic planning, and OR/MS.

While encouraging, the results of the proposed framework are context-dependent and subjective in nature, so extrapolations to other contexts can only be done with the proper adjustments. Thus, future research may want to consider using different methods and/ or replicating the processes followed in this study with a different group of decision makers in order to obtain other types of feedback. Although direct comparisons with other methods fell outside the scope of the present study, we recognize the importance of this and encourage other researchers to include comparisons. The methodological approach adopted in this study could also be extended to other contexts. Any additional progress will always be welcomed as a step closer to accurate evaluations of smart cities' components.

Records of the expert panel meetings, including photographs, software output and non-confidential information of the study, can be obtained from the corresponding author upon request. The authors thank the contribution and knowledge sharing of the expert panel members: Ana Cardoso, Bernardo Paiva, Francisco Manso, Francisco Pombas, Luís Carvalho, and Lea Lima. Facility support from the ISCTE Business School, University Institute of Lisbon, Portugal, is also acknowledged.

\section{References}

Ackermann, F., \& Eden, C. (2001). SODA - Journey making and mapping in practice. In J. Rosenhead, \& J. Mingers (Eds.), Rational analysis for a problematic world revisited: problem structuring methods for complexity, uncertainty and conflict (pp. 43-60). Chichester: John Wiley \& Sons.

Ahvenniemi, H., Huovila, A., PintoSeppä, I., \& Airaksinen, M. (2017). What are the differences between sustainable and smart cities? Cities, 60, 234-245. https://doi. org/10.1016/j.cities.2016.09.009.

Albayrak, A., \& Albayrak, M. (2016). Performance evaluation of practice courses using fuzzy cognitive maps. In 2016 15th International Conference on Information Technology Based Higher Education and Training (ITHET) (pp. 1-7). https://doi. org/10.1109/ITHET.2016.7760730.

Albino, V., Berardi, U., \& Dangelico, R. M. (2015). Smart Cities: Definitions, Dimensions, Performance, and Initiatives. Journal of Urban Technology, 22(1), 3-21. https://doi.org/10.1080/ 10630732.2014.942092.

Azevedo, A., \& Ferreira, F. (2017). Analyzing the dynamics behind ethical banking practices using fuzzy cognitive mapping. Operational Research. https://doi.org/10.1007/s12351-0170333-6.

Bakici, T., Almirall, E., \& Wareham, J. (2013). A Smart City Initiative: the Case of Barcelona. Journal of the Knowledge Economy, 4(2), 135-148. https://doi.org/10.1007/s13132012-0084-9.

Bell, S., \& Morse, S. (2013). Groups and facilitators within problem structuring processes. Journal of the Operational Research Society, 64(7), 959-972. https://doi.org/10.1057/jors.2012.110.

Carlucci, D., Schiuma, G., Gavrilova, T., \& Linzalone, R. (2013, June). A fuzzy cognitive map based approach to disclose value creation dynamics of ABls. Proceedings of the $8^{\text {th }}$ International Forum on Knowledge Asset Dynamics (IFKAD-2013) (pp. 207-219). Zagreb, Croatia.

Carvalho, J. (2013). On the semantics and the use of fuzzy cognitive maps and dynamic cognitive maps in social sciences. Fuzzy Sets and Systems, 214, 6-19. https://doi. org/10.1016/j.fss.2011.12.009.

Cauchon, D. (2017). The promise of smart cities. Electric Perspectives, 42(1), 34-41.

Chen, C., \& Chiu, Y. (2016). A study of fuzzy cognitive map model with dynamic adjustment method for the interaction weights. In 2016 International Conference on Advanced Materials for Science and Engineering (ICAMSE) (pp. 699-702). https://doi.org/10.1109/ICAMSE.2016.7840193. 
Dall'O', G., Bruni, E., Panza, A., Sarto, L., \& Khayatian, F. (2017). Evaluation of cities' smartness by means of indicators for small and medium cities and communities: A methodology for Northern Italy. Sustainable Cities and Society, 34, 193-202. https://doi.org/10.1016/j. scs.2017.06.021.

Estrada, E., Maciel, R., Ortíz Zezzatti, C., Bernabe-Loranca, B., Oliva, D., \& Larios, V. (2018). Smart City Visualization Tool for the Open Data Georeferenced Analysis Utilizing Machine Learning. International Journal of Combinatorial Optimization Problems and Informatics, 9(2), 25-40.

Faria, P., Ferreira, F., Jalali, M., Bento, P., \& António, N. (2018). Combining cognitive mapping and MCDA for improving quality of life in urban areas. Cities, 78, 116-127. https://doi. org/10.1016/j.cities.2018.02.006.

Fernandes, I., Ferreira, F., Bento, P., Jalali, M., \& António, N. (2018). Assessing sustainable development in urban areas using cognitive mapping and MCDA. International Journal of Sustainable Development \& World Ecology, 25(3), 216-226. https://doi.org/10.1080/135045 09.2017.1358221.

Ferreira, F., \& Jalali, M. (2015). Identifying key determinants of housing sales and timeon-the-market (TOM) using fuzzy cognitive mapping. International Journal of Strategic Property Management, 19(3), 235-244. https:// doi.org/10.3846/1648715X.2015.1052587.

Ferreira, F., Jalali, M., \& Ferreira, J. (2016a). Experience-focused thinking and cognitive mapping in ethical banking practices: From practical intuition to theory. Journal of Business Research, 69(11), 4953-4958. https:// doi.org/10.1016/j.jbusres.2016.04.058.

Ferreira, F., Jalali, M., \& Ferreira, J. (2016b). Integrating qualitative comparative analysis (QCA) and fuzzy cognitive maps (FCM) to enhance the selection of independent variables. Journal of Business Research, 69(4), 1471-1478. https://doi.org/10.1016/j. jbusres.2015.10.127.

Ferreira, F., Jalali, M., Ferreira, J., Stankevičienè, J., \& Marques, C. (2016c). Understanding the dynamics behind bank branch service quality in Portugal: pursuing a holistic view using fuzzy cognitive mapping. Service Business, 10(3), 469-487. https://doi. org/10.1007/s11628-015-0278-x.

Ferreira, F., Jalali, M., MeidutèKavaliauskienè, I., \& Viana, B. (2015).
A metacognitive decision making basedframework for bank customer loyalty measurement and management. Technological and Economic Development of Economy, 21(2), 280-300. https://doi.org/10.3846/202949 13.2014.981764.

Ferreira, F., Spahr, R., Sunderman, M., Banaitis, A., \& Ferreira, J. (2017). A learningoriented decision-making process for real estate brokerage service evaluation. Service Business, 11(3), 453-474. https://doi.org/10.1007/s11628016-0315-4.

Fonseca, M., Ferreira, F., Fang, W., \& Jalali, M. (2018). Classification and selection of tenants in residential real estate: a constructivist approach. International Journal of Strategic Property Management, 22(1), 1-11. https://doi. org/10.3846/ijspm.2018.317.

Gavrilova, T., Carlucci, D., \& Schiuma, G. (2013). Art of visual thinking for smart business education. In Proceedings of the 8th international forum on knowledge asset dynamics (IFKAD-2013). 12-14 June 2013, Zagreb, Croatia (pp. 1754-1761).

Glykas, M. (2013). Fuzzy cognitive strategic maps in business process performance measurement. Expert Systems with Applications, 40(1), 1-14. https://doi. org/10.1016/j.eswa.2012.01.078.

Gray, S., Gray, S., Cox, L., \& HenlyShepard, S. (2013). Mental Modeler: A FuzzyLogic Cognitive Mapping Modeling Tool for Adaptive Environmental Management. In 2013 46th Hawaii International Conference on System Sciences (pp. 965-973). https://doi. org/10.1109/HICSS.2013.399.

Hajduk, S. (2016). The concept of a smart city in urban management. Business, Management and Education, 14(1), 34-49. https://doi.org/10.3846/bme.2016.319.

Huovila, A., Airaksinen, M., Pinto-Seppä, I., Piira, K., Bosch, P., Penttinen, T., Neumann, H.-M., \& Kontinakis, N. (2017). CITYkeys smart city performance measurement system. International Journal for Housing Science and Its Applications, 41(2), 113-125.

Jorga, I., Mastrappas, S., \& Damigos, D. (2018). Identifying contributing factors to progress in karate-do using the fuzzy cognitive mapping approach. Ido Movement for Culture, Journal of Martial Arts Anthropology, 18(1), 1522. https://doi.org/10.14589/ido.18.1.3.

Keršulienè, V., \& Turskis, Z. (2011). Integrated fuzzy multiple criteria decision 
making model for architect selection. Technological and Economic Development of Economy, 17(4), 645-666. https://doi.org/10.38 46/20294913.2011.635718.

Khan, M., \& Quaddus, M. (2004). Group Decision Support Using Fuzzy Cognitive Maps for Causal Reasoning. Group Decision and Negotiation, 13(5), 463-480. https://doi. org/10.1023/B:GRUP.0000045748.89201.f3.

Khatoun, R., \& Zeadally, S. (2016). Smart cities: Concepts, architectures, research, opportunities. Communications of the ACM, 59(8), 46-57. https://doi.org/10.1145/2858789.

Kok, K. (2009). The potential of Fuzzy Cognitive Maps for semi-quantitative scenario development, with an example from Brazil. Global Environmental Change, 19(1), 122-133. https://doi.org/10.1016/j. gloenvcha.2008.08.003.

Kosko, B. (1986). Fuzzy cognitive maps. International Journal of Man-Machine Studies, 24(1), 65-75. https://doi.org/10.1016/S00207373(86)80040-2.

Lee, D., \& Lee, H. (2015). Construction of holistic Fuzzy Cognitive Maps using ontology matching method. Expert Systems with Applications, 42(14), 5954-5962. https://doi. org/10.1016/j.eswa.2015.03.020.

Mallapuram, S., Ngwum, N., Yuan, F., Lu, C., \& Yu, W. (2017). Smart city: The state of the art, datasets, and evaluation platforms. In 2017 IEEE/ACIS 16th International Conference on Computer and Information Science (ICIS) (pp. 447-452). https://doi.org/10.1109/ ICIS.2017.7960034.

Marques, S., Ferreira, F., MeidutèKavaliauskienè, I., \& Banaitis, A. (2018). Classifying urban residential areas based on their exposure to crime: A constructivist approach. Sustainable Cities and Society, 39, 418-429. https://doi.org/10.1016/j. scs.2018.03.005.

Mazlack, L. (2009). Representing Causality Using Fuzzy Cognitive Maps. In NAFIPS 2009 - 2009 Annual Meeting of the North American Fuzzy Information Processing Society (pp. 1-6). https://doi.org/10.1109/NAFIPS.2009.5156434.

Mls, K., Cimler, R., Vaščák, J., \& Puheim, M. (2017). Interactive evolutionary optimization of fuzzy cognitive maps. Advances in Fuzzy Cognitive Maps Theory, 232, 58-68. https://doi. org/10.1016/j.neucom.2016.10.068.

Oliveira, I., Carayannis, E., Ferreira, F., Jalali, M., Carlucci, D., \& Ferreira, J. (2018).
Constructing home safety indices for strategic planning in residential real estate: A sociotechnical approach. Technological Forecasting and Social Change, 131, 67-77. https://doi. org/10.1016/j.techfore.2017.10.012.

Papageorgiou, E., Hatwágner, M., Buruzs, A., \& Kóczy, L. (2017). A concept reduction approach for fuzzy cognitive map models in decision making and management. Neurocomputing, 232, 16-33. https://doi. org/10.1016/j.neucom.2016.11.060.

Papageorgiou, E., Roo, J., Huszka, C., \& Colaert, D. (2012). Formalization of treatment guidelines using Fuzzy Cognitive Maps and semantic web tools. Journal of Biomedical Informatics, 45(1), 45-60. https://doi. org/10.1016/j.jbi.2011.08.018.

Pires, A., Ferreira, F., Jalali, M., \& Chang, H. (2018). Barriers to real estate investments for residential rental purposes: mapping out the problem. International Journal of Strategic Property Management, 22(3), 168-178. https:// doi.org/10.3846/ijspm.2018.1541.

Popescu, G. (2015). The economic value of smart city technology. Economics, Management, and Financial Markets, 10(4), 76-82.

Ribeiro, M., Ferreira, F., Jalali, M., \& MeidutèKavaliauskienè, I. (2017). A fuzzy knowledgebased framework for risk assessment of residential real estate investments. Technological and Economic Development of Economy, 23(1), 140-156. https://doi.org/10.38 46/20294913.2016.1212742.

Roman, K. (2018). Analysis and evaluation of the implementation level of the smart city concept in selected polish cities. BRAIN Broad Research in Artificial Intelligence and Neuroscience, 9(1), 138-145.

Salmeron, J. (2012). Fuzzy cognitive maps for artificial emotions forecasting. Applied Soft Computing, 12(12), 3704-3710. https://doi. org/10.1016/j.asoc.2012.01.015.

Santos, F., Ferreira, F., \& MeidutèKavaliauskienè, I. (2018). Perceived key determinants of payment instrument usage: A fuzzy cognitive mapping-based approach. Technological and Economic Development of Economy, 24(3), 950-968. https://doi.org/10.38 46/20294913.2016.1261374.

Šiurytè, A., \& Davidavičienè, V. (2016). An analysis of key factors in developing a smart city. Science - Future of Lithuania, 8(2), 254-262. https://doi.org/10.3846/mla.2016.900. 
Sofronijević, A., Milićević, V., \& Ilić, B. (2014). Smart city as framework for creating competitive advantages in international business management. Management, 19(71), 5-15. https://doi.org/10.7595/management. fon.2014.0015.

Stach, W., Kurgan, L., Pedrycz, W., \& Reformat, M. (2005). Genetic learning of fuzzy cognitive maps. Fuzzy Sets and Systems, 153(3), 371-401. https://doi.org/10.1016/j. fss.2005.01.009.

Stylios, C., \& Groumpos, P. (1998). The challenge of modelling supervisory systems using fuzzy cognitive maps. Journal of Intelligent Manufacturing, 9(4), 339-345. https://doi.org/10.1023/A:1008978809938.

Swan, J. (1997). Using Cognitive Mapping in Management Research: Decisions about Technical Innovation. British Journal of Management, 8(2), 183-198. https://doi.org/10.1111/1467-8551.0050.

Tegarden, D., \& Sheetz, S. (2003). Group cognitive mapping: a methodology and system for capturing and evaluating managerial and organizational cognition. Omega, 31(2), 113-125. https://doi.org/10.1016/S0305-0483(03)00018-5.

Tolman, E. (1948). Cognitive maps in rats and men. Psychological Review, 55(4), 189-208. http://dx.doi.org/10.1037/h0061626.

Toschi, G., Campos, L., \& Cugnasca, C. (2017). Home automation networks: A survey. Computer Standards \& Interfaces, 50, 42-54. https://doi.org/10.1016/j.csi.2016.08.008.

Village, J., Greig, M., Salustri, F., \& Neumann, W. (2012). Linking human factors to corporate strategy with cognitive mapping techniques. International Ergonomics Association Conference, 41(1), 2776-2780.

Wong, C. (2010). Cognitive mapping on user interface design. In 2010 International Conference on Computer Applications and Industrial Electronics (pp. 288-293). https://doi. org/10.1109/ICCAIE.2010.5735091.

Yaman, D., \& Polat, S. (2009). A fuzzy cognitive map approach for effect-based operations: An illustrative case. Information Sciences, 179(4), 382-403. https://doi. org/10.1016/j.ins.2008.10.013.

Zadeh, L. (2008). Is there a need for fuzzy logic? Information Sciences, 178(13), 2751-2779. https://doi.org/10.1016/j.ins.2008.02.012.
Bárbara P. Miguel University Institute of Lisbon ISCTE Business School

Portugal bpmls@iscte-iul.pt

Prof. Fernando A. F. Ferreira, Ph.D. BRU-IUL, University Institute of Lisbon ISCTE Business School Portugal and University of Memphis Fogelman College of Business and Economics USA fernando.alberto.ferreira@iscte.pt fernando.ferreira@memphis.edu

Prof. Audrius Banaitis, Ph.D. Vilnius Gediminas Technical University Faculty of Civil Engineering Department of Construction Management and Real Estate Lithuania audrius.banaitis@vgtu.It

Assoc. Prof. Nerija Banaitienè, Ph.D. Vilnius Gediminas Technical University Faculty of Civil Engineering Department of Construction Management and Real Estate Lithuania nerija.banaitiene@vgtu.It

Assoc. Prof. leva Meidutè-Kavaliauskienè, Ph.D. Research Centre, General Jonas Žemaitis Military Academy of Lithuania Lithuania and BRU-IUL, University Institute of Lisbon Portugal ieva.meidute@lka.It

Assist. Prof. Pedro F. Falcão, Ph.D. BRU-IUL, University Institute of Lisbon ISCTE Business School Portugal pfontesfalcao@iscte-iul.pt 


\title{
Abstract
}

\section{AN EXPANDED CONCEPTUALIZATION OF "SMART" CITIES: ADDING VALUE WITH FUZZY COGNITIVE MAPS}

\author{
Bárbara P. Miguel, Fernando A. F. Ferreira, Audrius Banaitis, \\ Nerija Banaitienė, leva Meidutė-Kavaliauskienè, Pedro F. Falcão
}

The world's rapidly growing population is an issue to be taken seriously. Its consequences could be dramatic if the required steps are not taken. Concerns about this problem have led to the creation of "smart" cities, which promote improvements in citizens' quality of life through a combination of new technologies and environmentally sustainable practices. For these cities to be truly "smart", they need to be evaluated in order to understand the areas in which interventions are necessary to make these cities economically stable and environmentally sustainable. In this regard, various studies have sought to understand which indicators should be considered in assessments of smart cities and how this process should be conducted. Thus far, however, researchers have found that using "loose" indicators, which measure only some areas of these cities, is insufficient. That said, this study proposes the use of fuzzy cognitive maps to analyze the dynamics behind smart cities' components. Grounded in intensive group meetings with a panel of experts in different dimensions of these cities, the method applied produced a well-informed, process-oriented framework that contains the characteristics and components that should be assessed in this type of city. Specifically, after a fuzzy cognitive map was constructed based on the direct involvement of the expert participants, six main clusters were extracted as key components in the development of smart cities. These clusters were: people; planning and environments; technology; infrastructure and materials; services; and transportation and mobility. The results also facilitate an improved understanding of smart cities' cause-and-effect relationships and better strategic planning by urban planners and city administrators. The implications, advantages, and limitations of the proposed framework are also presented.

Key Words: Smart, smart city, smart economy, smart environment, smart governance, smart mobility, cause-and-effect dynamics, fuzzy cognitive mapping.

JEL Classification: C44, C45, M10, R11.

DOI: 10.15240/tul/001/2019-1-001 